\title{
Iron deficiency causes a shift in AMP-activated protein kinase (AMPK) subunit composition in rat skeletal muscle
}

\author{
John F Merrill', David M Thomson' ${ }^{1}$, Shalene E Hardman', Squire D Hepworth², Shelby Willie \\ and Chad R Hancock ${ }^{2^{*}}$
}

\begin{abstract}
Background: As a cellular energy sensor, the 5'AMP-activated protein kinase (AMPK) is activated in response to energy stresses such as hypoxia and muscle contraction. To determine effects of iron deficiency on AMPK activation and signaling, as well as the AMPK subunit composition in skeletal muscle, rats were fed a control (C=50-58 mg/kg Fe) or iron deficient (ID=2-6 mg/kg Fe) diet for 6-8 wks.

Results: Their respective hematocrits were $47.5 \% \pm 1.0$ and $16.5 \% \pm 0.6$. Iron deficiency resulted in $28.3 \%$ greater muscle fatigue $(p<0.01)$ in response to 10 min of stimulation $(1 \mathrm{twitch} / \mathrm{sec})$ and was associated with a greater reduction in phosphocreatine (C: Resting $24.1 \pm 0.9 \mu \mathrm{mol} / \mathrm{g}$, Stim $13.1 \pm 1.5 \mu \mathrm{mol} / \mathrm{g}$; ID: Resting $22.7 \pm 1.0 \mu \mathrm{mol} / \mathrm{g}$, Stim $3.2 \pm 0.7 \mu \mathrm{mol} / \mathrm{g} ; \mathrm{p}<0.01$ ) and ATP levels (C: Resting $5.89 \pm 0.48 \mu \mathrm{mol} / \mathrm{g}$, Stim $6.03 \pm 0.35 \mu \mathrm{mol} / \mathrm{g}$; ID: Resting $5.51 \pm 0.20 \mu \mathrm{mol} / \mathrm{g}$, Stim $4.19 \pm 0.47 \mu \mathrm{mol} / \mathrm{g} ; \mathrm{p}<0.05)$. AMPK activation increased with stimulation in muscles of $C$ and ID animals. A reduction in Cytochrome $\mathrm{c}$ and other iron-dependent mitochondrial proteins was observed in ID animals $(p<0.01)$. The AMPK catalytic subunit (a) was examined because both isoforms are known to play different roles in responding to energy challenges. In ID animals, AMPKa2 subunit protein content was reduced to $71.6 \%$ of $C(p<0.05)$, however this did not result in a significant difference in resting AMPKa2 activity. AMPKa1 protein was unchanged, however an overall increase in AMPKa1 activity was observed (C: $0.91 \mathrm{pmol} / \mathrm{mg} / \mathrm{min} ; \mathrm{ID}: 1.63 \mathrm{pmol} / \mathrm{mg} /$ min; $p<0.05$ ). Resting phospho Acetyl CoA Carboxylase (pACC) was unchanged. In addition, we observed significant reductions in the $\beta 2$ and $\gamma 3$ subunits of AMPK in response to iron deficiency.
\end{abstract}

Conclusions: This study indicates that chronic iron deficiency causes a shift in the expression of AMPKa, $\beta$, and $\gamma$ subunit composition. Iron deficiency also causes chronic activation of AMPK as well as an increase in AMPKa1 activity in exercised skeletal muscle.

Keywords: AMPK, AMPK alpha, Iron deficiency, Anemia, Energy metabolism, Skeletal muscle

\section{Background}

Iron is important for oxygen transport and ATP synthesis. If these processes are impaired by iron deficiency, cellular adaptations occur, such as an increased glucose dependence, in response to that deficiency [1,2]. The 5'AMPactivated protein kinase (AMPK) has been characterized as a major cellular energy sensor [3], which may mediate some of these adaptations. AMPK is activated in response

\footnotetext{
* Correspondence: chad hancock@byu.edu

${ }^{2}$ Department of Nutrition, Dietetics, and Food Science, Brigham Young University, Provo, Utah, USA

Full list of author information is available at the end of the article
}

to energy challenges such as hypoxia, muscle contraction, and hypoglycemia. Therefore, because AMPK is central to how cells respond to changes in the energy status of the cell and iron homeostasis is critical for the transduction of energy within the cell, we set out to investigate the effects of iron deficiency on AMPK activation and signaling. Ultimately we believe that this information may help elucidate why specific cellular responses occur with changes in cellular iron status.

Iron deficiency is the most common worldwide nutrient deficiency. Of the world's total population, $24.8 \%$ of individuals are anemic [4]. Anemia occurs at all stages of the life

\section{Biomed Central}


cycle, in both developing and developed countries, being most prevalent in pregnant women and young children ( $41.8 \%$ and $47.4 \%$ respectively) [4]. Iron deficiency is a metabolic stress because it compromises both the capacity for oxygen supply to tissues (anemia), as well as the capacity to utilize oxygen due to impairment of mitochondrial capacity [5]. This type of energetic stress, due to either decreased oxygen supply or utilization, has been shown to cause an increase in AMPK activation [6].

AMPK is a cellular energy sensor that when activated, stimulates catabolic processes that increase ATP synthesis, and concurrently inhibits anabolic processes that consume ATP [7]. Nutritional or environmental stress, such as hypoglycemia, hypoxia, and/or muscle contraction, lead to an increase in the AMP:ATP ratio [8]. The function of the enzyme is altered by the interaction of the AMPK subunits as conformational changes occur. AMPK is a heterotrimer consisting of one alpha catalytic subunit and two regulatory subunits, beta and gamma [9], and multiple isoforms of all subunits have been identified $(\alpha 1, \alpha 2, \beta 1, \beta 2$, $\gamma 1, \gamma 2, \gamma 3)[10,11]$. AMPK complexes containing the $\alpha 2$ isoform are more sensitive to changes in AMP concentration than are complexes containing $\alpha 1$ [12]. Furthermore each isoform of the $\alpha$ subunit affects different downstream signaling pathways. For example, the $\alpha 1$ subunit is more important in the inhibition of protein synthesis via the mTOR pathway $[13,14]$. The activation of AMPK is largely determined by phosphorylation of $\mathrm{Thr}^{172}$ on the $\alpha$ subunit, which causes a greater than 20-fold increase in activity [3]. This is primarily done by the predominant AMPK kinase in skeletal muscle, LKB1 $[15,16]$, and is enhanced when the AMP:ATP ratio is high by nucleotide binding to the $\gamma$ subunit of AMPK [17]. Binding of AMP to the $\gamma$ subunit increases activation of AMPK by up to fivefold, but also makes AMPK a poorer substrate for the phosphatase and increases phosphorylation by LKB1 (a net increase in activity of $>1000$-fold) $[18,19]$. Conversely, when the AMP:ATP ratio is low, the nucleotide binding sites on $\gamma$ are occupied by ATP, eliminating inhibition of the phosphatase, decreasing net enzymatic activity [20].

Exercise is a metabolic stress on the cell, which has been shown to increase the activation of AMPK [21,22]. Muscle contraction during exercise increases the AMP:ATP ratio because excitation-contraction coupling depends on the hydrolysis of ATP to ADP as its source of energy. Myokinase catalyzes a reaction that transfers a phoshoryl group from one ADP to another, which regenerates one ATP, and forms one AMP (2 ADP $\rightarrow$ ATP + AMP). This reaction is important for limiting the increase in ADP when the rate of ATP hydrolysis is high, and thus results in an increase in the AMP:ATP ratio [3,23,24]. The concerted effects of iron deficiency and muscle contraction on AMPK activation however are still unknown. A muscle cell that is metabolically stressed due to iron deficiency may be even more adversely affected by exercise than an iron sufficient cell. This increased stress likely has consequences on AMPK activation and signaling.

The effects of hypoxia on AMPK activation have been documented [25], as well as the adverse effects of iron deficiency on mitochondrial enzyme content [5,26,27], and AMPK phosphorylation due to iron deficiency [6]. The objective of this study was to examine: 1) the extent to which chronic AMPK activation occurs due to iron deficiency, 2) how AMPK activation and signaling due to muscle stimulation is affected during iron deficiency, and 3) the effects of iron deficiency on the AMPK subunit composition in skeletal muscle.

\section{Results}

\section{Degree of iron deficiency}

Animals fed a diet deficient in iron content became anemic by 6 weeks of feeding. This was evident by a significant reduction of both hematocrit and hemoglobin (Figures 1A and 1B).

Body Mass. Mean body mass of both $\mathrm{C}$ and ID groups were not different on day 0 of treatment at 21 days of age. On day 11 , the mean body mass of the $C$ group was $20 \%$ greater than that of the ID group. Due to this large disparity between the two groups we began pair feeding the $\mathrm{C}$ group to the ID group on day 13. The $\mathrm{C}$ group continued, however, to grow at a higher rate than the ID group. After 6 weeks of treatment, the majority of that being pair feeding, the mean body mass of the $C$ group was $282 \pm 3 \mathrm{~g}$, while that of the ID group was $167 \pm 5 \mathrm{~g}$ (Figure 2). The ratio of the tibialis anterior muscle mass to the body mass was measured to determine whether growth of the skeletal muscle was proportionate to total body growth. This ratio was not different between the two groups (C: $1.86 \mathrm{mg}$ muscle weight/g body weight \pm 0.06 ; ID: $1.87 \mathrm{mg}$ muscle weight/g body weight \pm 0.03 ).

\section{Effect of iron deficiency on mitochondrial enzyme expression}

The electron transport chain (ETC.) of the mitochondria depends on iron as an electron acceptor/donor at multiple steps of electron transport. Cytochrome c, Cytochrome c oxidase I (COX1), and Succinate Dehydrogenase are all iron-dependent enzymes of the ETC. Because they depend on iron for enzymatic activity, it would be expected that their protein content would decrease with iron deficiency. All three of these enzymes decreased significantly with iron deficiency $(\mathrm{p}<0.01)$ (Figure 3$)$, confirming that iron deficiency created a situation of significant energy insult.

\section{Skeletal muscle fatigue}

It has been shown that muscle contraction causes an increase in AMPK activity [28]. In order to further show differences in AMPK activation due to iron deficiency, 

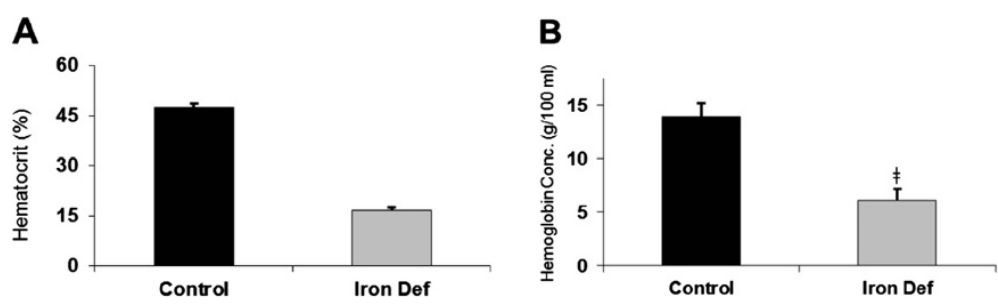

Figure 1 Plasma hematocrit and hemoglobin concentration. A. Hematocrit decreased dramatically with iron deficiency (₹ indicates statistical significance, $p<0.01)(n=4)$. B. Hemoglobin concentration decreased significantly with iron deficiency ( $\neq$ indicates statistical significance, $p<0.01)(n=4)$

in situ muscle stimulation was performed. In past studies with a low-demand stimulation protocol similar to ours, oxygen has been supplied during muscle stimulation, and $C$ rats showed little or no fatigue [29]. Therefore, in the present study, oxygen was supplied to both the $\mathrm{C}$ and ID groups to limit the oxygen deficit due to anemia and increase our ability to focus on muscle specific effects of iron deficiency. Evidence that this approach was successful in limiting the hypoxia of the control rats includes: 1) the resting concentration of phosphocreatine was not different between $\mathrm{C}$ and ID muscles and 2) a difference in AMPK activity under these conditions was not observed at rest, as others have shown [6]. Although this did serve to limit the oxygen deficit, it did not eliminate it completely. Hemoglobin concentration in the ID rats was reduced by about half, meaning that the ID rats only had about $50 \%$ of the oxygen carrying capacity of the $C$ rats. Even with supplementation of $100 \%$ oxygen, the ID rats during stimulation were likely hypoxic compared to the $\mathrm{C}$ rats.

The mean initial force generated by the $C$ group was $39 \%$ greater than that generated by the ID group (C: $601 \pm$ $42 \mathrm{~g}$; ID: $433 \pm 34 \mathrm{~g}$ ). Although the mean body mass of the $\mathrm{C}$ group was greater, the amount of force generated by the right hindlimb GPS complex per gram of muscle mass was not different between the two groups (C: $0.24 \pm 0.03$ $\mathrm{g} / \mathrm{mg}$ muscle; $0.32 \pm 0.04 \mathrm{~g} / \mathrm{mg}$ muscle). In order to analyze relative fatigue, force data was analyzed as a percent of the initial force generated by each group during the 10 minutes of stimulation. Although within the first 1-2 minutes of stimulation, the amount of force generated by the two groups increased, the force generated by the ID group dropped to $72 \%$ of the initial force after 10 minutes of stimulation, whereas the $C$ group was able to generate $100 \%$ of the initial force by the end of the same 10-minute period (Figure 4). Thus, this stimulation protocol was mild enough to limit any net fatigue in the control rats over the course of 10 minutes.

\section{High energy phosphates}

Aside from the major mechanisms of ATP synthesis from carbohydrate and fatty acid substrates, the concentration of ATP is buffered through the creatine kinase system. In addition, an increase in the concentration of ADP during exercise is limited by the myokinase reaction $(2 \mathrm{ADP} \longleftrightarrow \mathrm{ATP}+\mathrm{AMP})$, resulting in an increase in AMP. Much of that AMP is then converted to IMP by AMP deaminase. This buffering action by creatine kinase and myokinase as well as the continual supply of ATP from oxidative phosphorylation limits any net reduction in ATP under most energy demands. During high energy demands, muscle AMP and IMP increase, while ATP and phosphocreatine decrease. The purpose of measuring the concentration of high-energy phosphates in these muscles tissues was to determine and compare the cellular energy state of the ID and $\mathrm{C}$ groups. An increase in ADP and AMP, is associated with activation of AMPK [30].

Phosphocreatine levels decreased in the $\mathrm{C}$ group by $45.9 \%$ during the 10 -minute stimulation period. In the ID group however, phosphocreatine levels were reduced by 85.9\% (Table 1). IMP concentration increased modestly in $\mathrm{C}$ rats during stimulation (3.6-fold), but increased by a much larger amount in ID rats (8.7-fold) (Table 1$)$. There was also a large increase in estimated free concentration

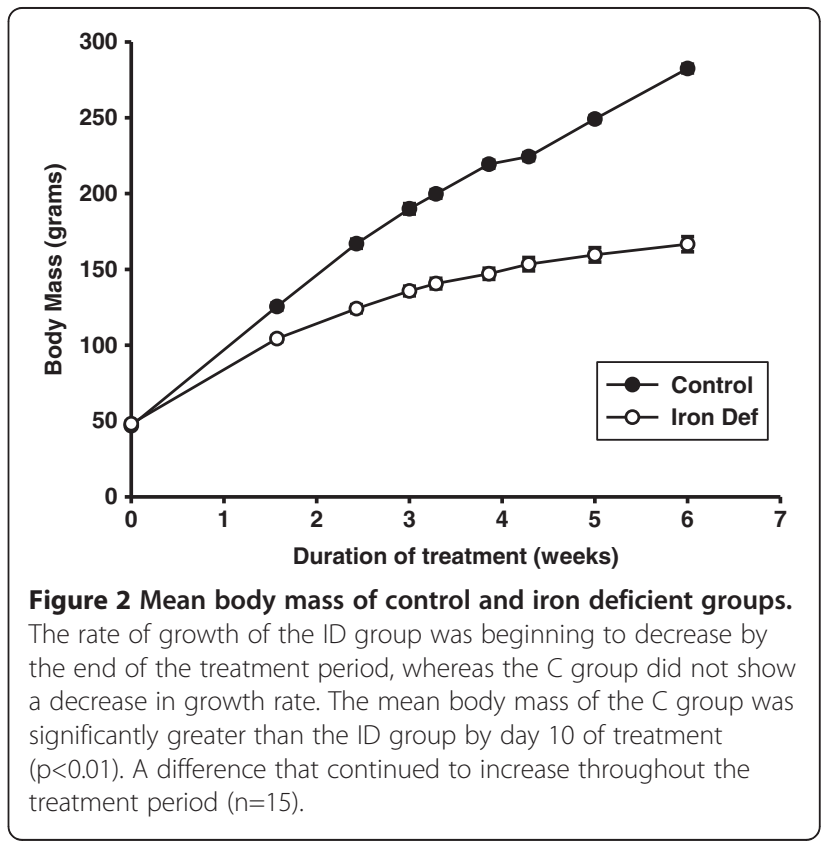




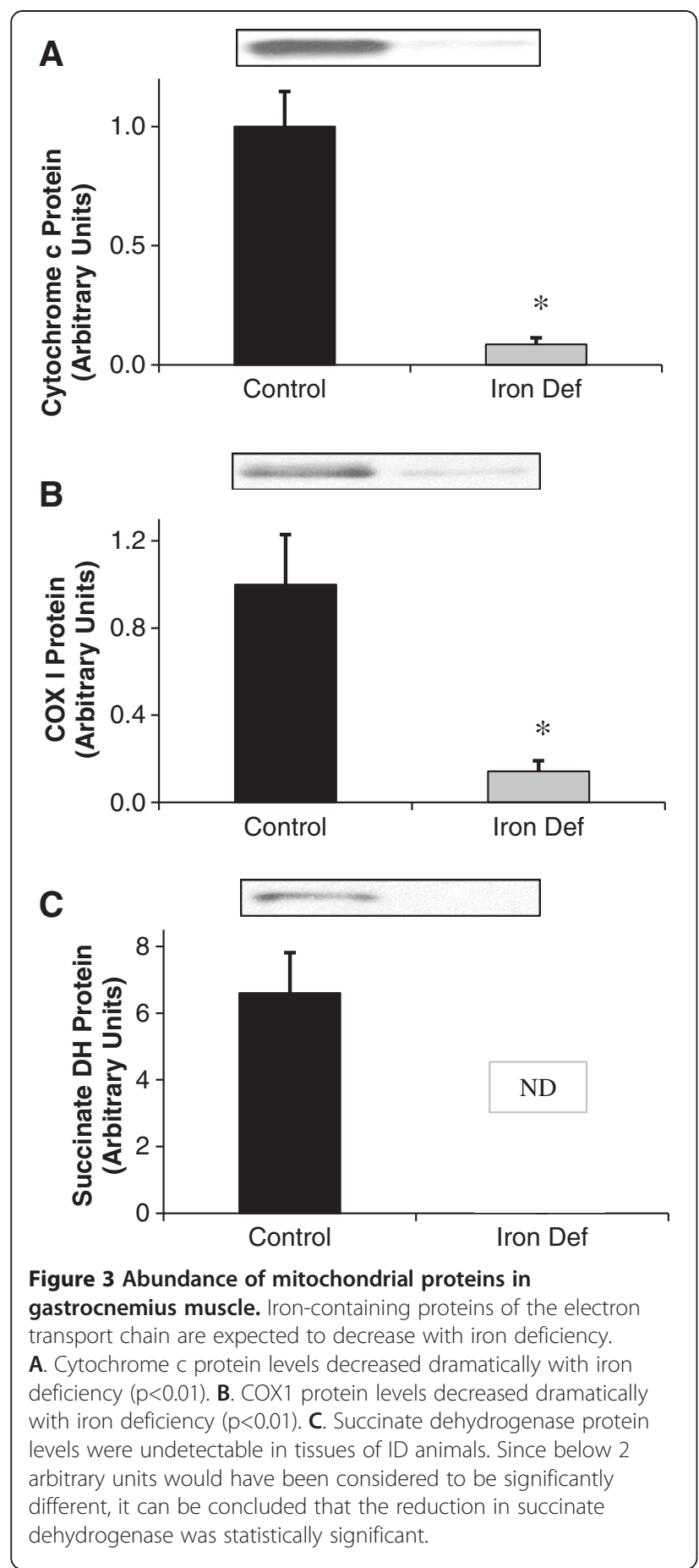

of AMP with stimulation in the ID rats $(2.07 \pm 1.06 \mathrm{vs}$. $0.17 \pm 0.09 \mathrm{nmol} / \mathrm{g}$ wet wt in ID compared to control muscles), which approached statistical significance $(p=0.05)$. These data confirm that while the stimulation protocol was mild (no net fatigue in the controls) the iron deficient rats sustained a much greater challenge to the energy state.

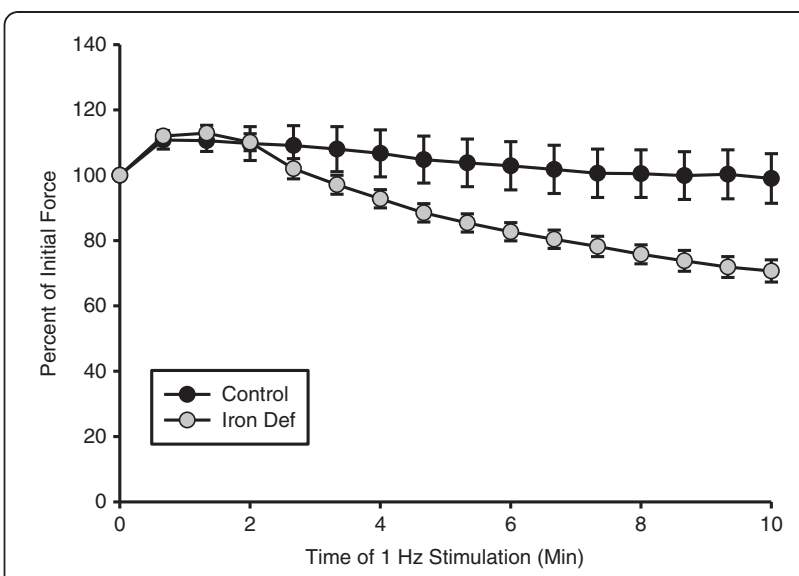

Figure 4 Force of muscle contraction. Fatigue was much greater in the ID group as evidence by the drop off in force that they were able to generate after continued $1 \mathrm{~Hz}$ muscle stimulation. After 6 $\min 40 \mathrm{sec}$ the amount of force generated by the $C$ rats was significantly greater than that of the ID rats $(p<0.01)(n=11-14)$.

\section{Analysis of AMPK activation}

After establishing that the ID rats were iron deficient and that this did create a metabolic stress, we examined the effects of chronic iron deficiency and in situ muscle stimulation on activation of the two AMPK $\alpha$ isoforms. In accordance with previous findings [21,22], the overall effect of stimulation was a significant increase in activation of both AMPK $\alpha$ isoforms in both the $C$ and ID groups. The two AMPK $\alpha$ isoforms, however, were affected differently by iron deficiency. Although it has been shown to be more AMP-dependent than AMPK $\alpha 1$ [12], resting AMPK $\alpha 2$ activity was not significantly different between the $C$ and ID groups (Figure 5A). Iron deficiency however did cause an increase in resting AMPK $\alpha 1$ activity which approached statistical significance $(p=0.05)$. Also, activation of AMPK $\alpha 1$ did not increase significantly due to stimulation in the $C$ group alone, but in the ID group, stimulation did result in a significant increase in AMPK $\alpha 1$ activation $(p=0.05)$ (Figure 5B).

Table 1 High energy phosphate concentrations in gastrocnemius muscle

\begin{tabular}{lccccc}
\hline & \multicolumn{2}{c}{ Control } & & \multicolumn{2}{c}{ Iron Def } \\
\cline { 2 - 3 } \cline { 5 - 6 } & Rest & Stim & & Rest & Stim \\
\hline ATP $(n=6-8)$ & $5.89 \pm 0.48$ & $6.03 \pm 0.35$ & & $5.51 \pm 0.20$ & $4.19 \pm 0.47 \neq$ \\
ADP $(n=6-8)$ & $0.79 \pm 0.08$ & $0.96 \pm 0.07$ & & $0.73 \pm 0.03$ & $1.03 \pm 0.07$ \\
AMP (n=6-8) & $0.06 \pm 0.01$ & $0.09 \pm 0.02$ & & $0.05 \pm 0.00$ & $0.16 \pm 0.06$ \\
$\operatorname{IMP}(n=6-8)$ & $0.22 \pm 0.01$ & $0.80 \pm 0.30$ & & $0.26 \pm 0.02$ & $2.26 \pm 0.63 \neq$ \\
$\operatorname{PCr}(n=9-10)$ & $24.1 \pm 0.9$ & $13.1 \pm 1.5$ & & $22.7 \pm 1.0$ & $3.2 \pm 0.7 \neq$ \\
$\operatorname{Cr}(n=9-10)$ & $15.8 \pm 1.1$ & $28.3 \pm 2.3$ & & $19.2 \pm 0.9$ & $37.0 \pm 1.8 \neq$ \\
\hline
\end{tabular}

Values are means $\pm \mathrm{SE}$ in a mol/g wet wt. $P C r$, phosphocreatine; $\mathrm{Cr}$, creatine. ₹ Significantly different from control $(p<0.01)$. 
Since AMPK is activated by phosphorylation, the ratio of the expression of phosphoAMPK to total AMPK $\alpha$ is also a reflection of total AMPK activation. This ratio did not increase significantly due to iron deficiency. It did, however increase with stimulation of both the $\mathrm{C}$ and ID groups (Figure 5C).

Acetyl CoA Carboxylase (ACC) is a downstream substrate of AMPK, and is inhibited by phosphorylation. The ratio of expression phosphoACC to total ACC was therefore used as an additional indicator of AMPK activation. Although ACC phosphorylation did increase greatly with stimulation, it did not increase significantly in rested tissues with iron deficiency (Figure 5D).

\section{Analysis of AMPK subunit expression}

Alpha subunits:AMPK complexes containing the $\alpha 2$ isoform sense and respond differently to energy stresses than AMPK complexes containing the $\alpha 1$ isoform. AMPK $\alpha 2$ is more sensitive to changes in AMP concentration than AMPK $\alpha 1$ [12]. AMPK $\alpha 2$ protein content decreased significantly $(\mathrm{p}<0.05)$ (Figure 6A), while AMPK $\alpha 1$ did not change significantly (Figure 6B). These data suggest a slight shift in the AMPK $\alpha$ subunit composition due to the chronic stress of iron deficiency. A non-isoform-specific AMPK pan $\alpha$ antibody was also used to quantitate expression of total AMPK, which was determined to be unchanged with iron deficiency (Figure 6C). Beta and gamma subunits: In addition to the $\alpha$ subunit expression, we also examined the expression of the regulatory $\beta$ and $\gamma$ subunits. While there were no differences in the expression of the $\beta 1, \gamma 1$ and $\gamma 2$ subunits (Figure $7 \mathrm{~A}, \mathrm{C}$ and $\mathrm{D}$ ), there was a significant reduction in both the $\beta 2$ (Figure $7 \mathrm{~B}$ ) and $\gamma 3$ (Figure 7E) subunits in response to severe iron deficiency.

\section{Chronic activation of AMPK}

Treatment with AICAR (a chemical activator of AMPK) has been shown to increase expression of Hexokinase II in skeletal muscle [31]. Therefore, we examined Hexokinase II expression as an indicator of chronic AMPK activation and found it to be increased dramatically with iron deficiency $(\mathrm{p}<0.01)$ (Figure 8A).

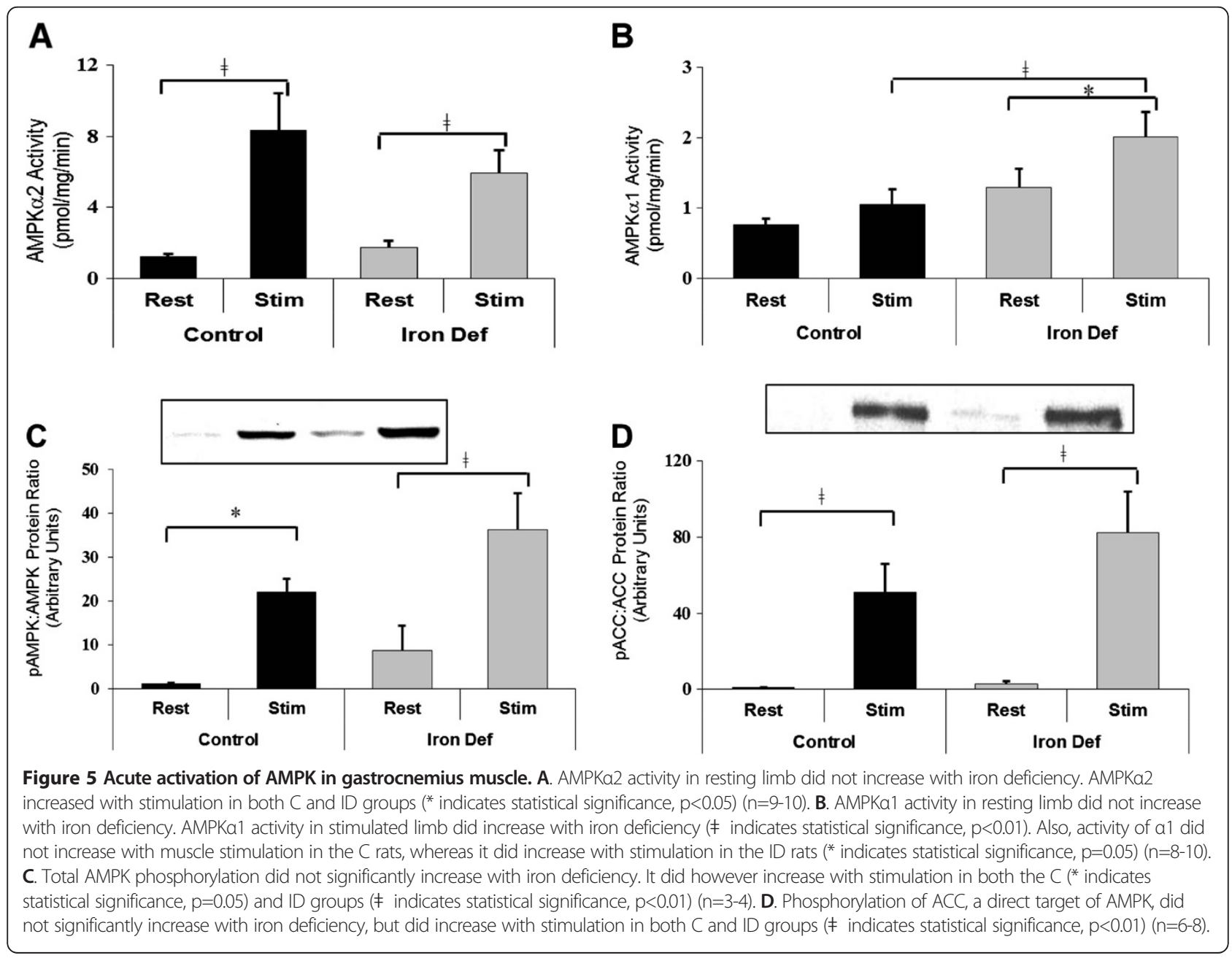




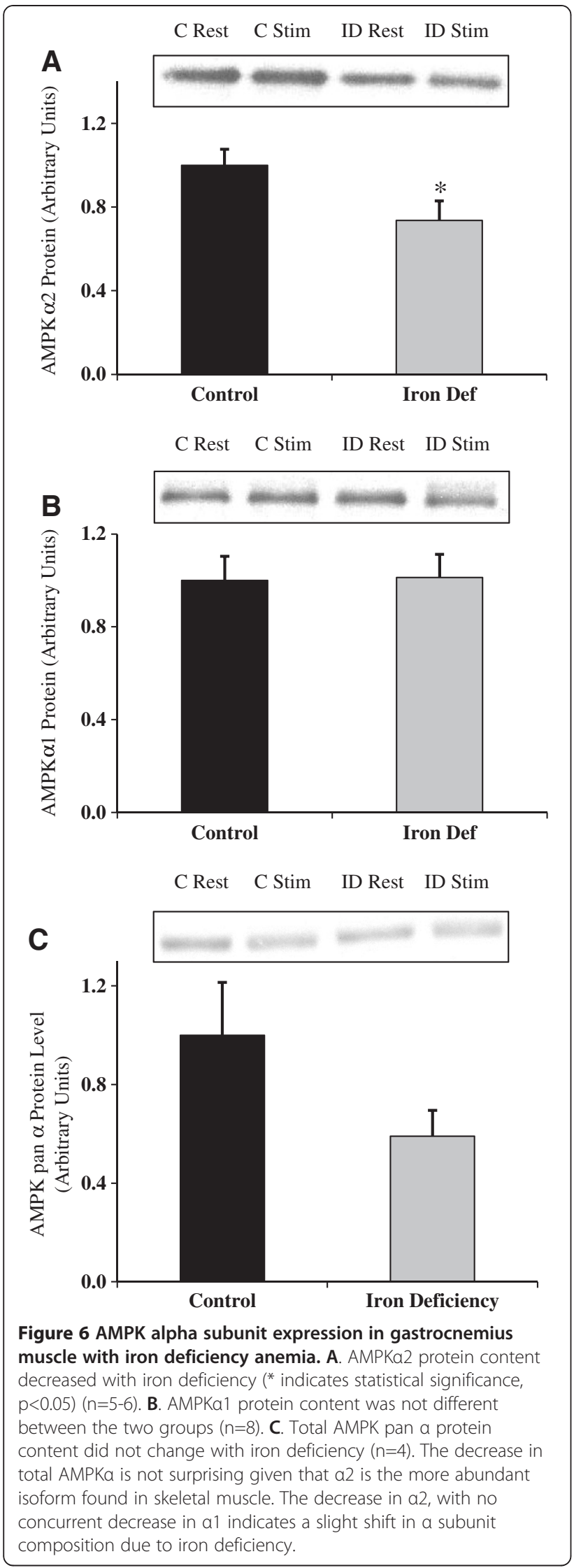

Citrate synthase is the first enzyme in the citric acid cycle. It can be upregulated by chronic activation of AMPK. Western blot data for citrate synthase revealed that its expression was not changed with iron deficiency (Figure 8B). Citrate synthase activity data also revealed no change with iron deficiency (Figure 8C).

\section{Discussion}

AMPK is a key regulator of cellular energy homeostasis. It becomes activated by various energy challenges which result in an increase in the AMP:ATP ratio. Iron deficiency is one such energy challenge. It results in a decrease in the iron-containing enzymes of the electron transport chain, without affecting the non-iron dependent enzymes of the citric acid cycle [27]. These changes lead to a decrease in muscle respiratory capacity as well as increased susceptibility to fatigue [26]. The ability of AMPK to sense energetic insults such as this leads to the question as to whether its activity increases, and how its expression and signaling are affected during iron deficiency. Following 6-8 weeks of treatment, AMPK $\alpha 2$ expression in ID animals was reduced significantly compared to $C(p<0.05)$. AMPK $\alpha 1$ expression was not different as a result of iron deficiency. Under the conditions in this study, iron deficiency did not result in a difference in resting AMPK $\alpha 2$ activity. Interestingly, iron deficiency did cause an increase in resting AMPK $\alpha 1$ activity, which approached statistical significance $(\mathrm{p}=0.05)$. Also, muscle stimulation did not result in increased activation of AMPK 1 in the C group, but in the ID group, stimulation did result in a significant increase in AMPK $\alpha 1$ activity $(\mathrm{p}=0.05)$. When the $\beta$ and $\gamma$ subunits were examined, significant reductions were observed in both the $\beta 2$ and $\gamma 3$ subunits of AMPK. The novel findings of this study are that chronic iron deficiency causes a shift in the expression of AMPK $\alpha, \beta$ and $\gamma$ subunit composition as well as potentially altered sensitivity of AMPK $\alpha 1$ and AMPK $\alpha 2$ to energy challenges such as muscle contraction.

\section{Iron deficiency anemia causes a shift in AMPK subunit composition}

Muscle contraction in ID rats resulted in a greater increase in AMPK $\alpha 1$ activation than in $C$ rats. Increased AMPK phosphorylation, or covalent activation of AMPK, occurs when an increase in the AMP:ATP ratio results in AMP binding to the $\gamma$ subunit. More recent work has also proposed a role for ADP in addition to AMP in the allosteric regulation of AMPK (see recent review by Hardie, Carling and Gamblin [30]). AMP binding directly to the $\gamma$ subunit results in allosteric activation of AMPK, which alone, increases activity by up to fivefold [18]. AMPK $\alpha 2$ is more responsive to an increase in the concentration of free AMP $\left(\mathrm{AMP}_{\mathrm{f}}\right)$ than AMPK $\alpha 1$ [12]. In our calculation of the difference of $\mathrm{AMP}_{\mathrm{f}}$ concentration between $\mathrm{C}$ and ID 


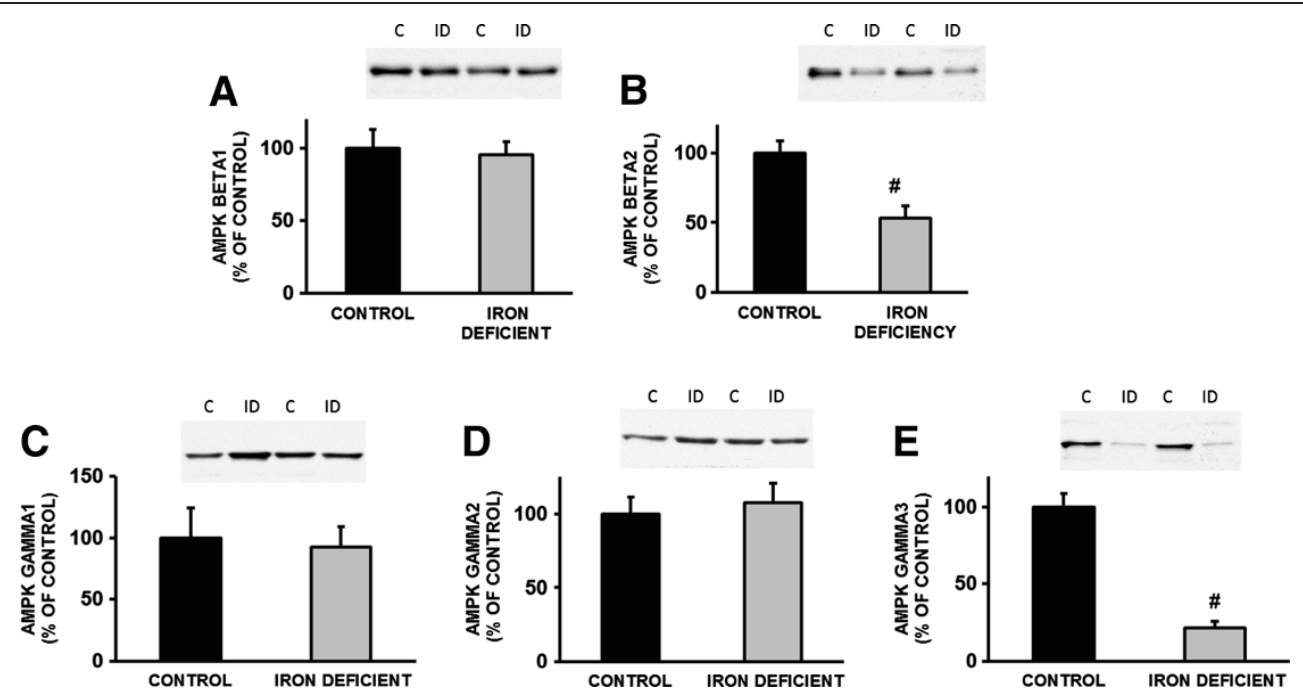

Figure 7 AMPK beta and gamma subunit expression following irion deficiency anemia in rat gastrocnemius muscle. A. AMPK b1 subunit expression was not different in response to iron deficiency. B. AMPK b2 subunit expression was reduced with iron deficiency in response to iron deficiency $(p<0.01)$. No changes were observed with AMPK $g 1$ (C) or g2 (D) subunit expression in response to iron deficiency, however a marked reduction was observed with $\mathrm{g} 3$ subunit expression $(\mathrm{p}<0.001)(\mathbf{E})$.

groups with stimulation, we did not achieve strong statistical significance because of the large variability between samples. An increase in $\mathrm{AMP}_{\mathrm{f}}$ concentration however, can be assumed based on the significant increase in IMP concentration, since IMP is a product of AMP deamination. Interestingly, we did not see a change in AMPK $\alpha 2$ activity with iron deficiency, even though the HPLC data confirms an increase in the concentration of IMP in the iron deficient, stimulated muscles. Of particular interest is the finding that AMPK $\alpha 1$ activity did increase with iron deficiency. Therefore, there is an apparent inconsistency with the energy status and the AMPK activity data. The protocol used to assess AMPK activity however, fails to reflect the allosteric activation of AMPK that is to be expected with the elevated levels of IMP and $\mathrm{AMP}_{\mathrm{f}}$ that were seen in the ID rats following muscle stimulation. Unlike our in vitro method of measuring AMPK activity, measuring phosphorylation of ACC should account for the allosteric activation of AMPK, as this is a method of measuring total in vivo AMPK activity. However, protein analyses indicate that muscle stimulation in the ID rats did not cause a greater increase in ACC phosphorylation than in $\mathrm{C}$ rats. This suggests that the reasons for the increase in AMPK $\alpha 1$ activity with muscle stimulation in the ID group may be due to more than just the change in energy status. One possible explanation is the fact that AMPK $\alpha 1$ activity has been shown to increase with overload of the plantaris muscle in $\mathrm{LKB1}^{-/-}$mice, with a concurrent increase in CaMKK activity [32]. This suggests that AMPK $\alpha 1$ is the preferred target for CaMKK, a known upstream kinase of AMPK. Further testing to determine if CaMKK activation is altered due to iron deficiency is necessary in order to confirm this assumption.

Since activation of AMPK $\alpha 1$ increased significantly with stimulation in ID animals, we conclude that there may be an increase in the contribution of AMPK $\alpha 1$ to total AMPK activity with iron deficiency. This is not to say that the contribution of AMPK 1 became greater than that of AMPK $\alpha 2$ to total AMPK activity (AMPK $\alpha 2$ activity still increased more with stimulation in the ID group than AMPK $\alpha 1$ activity). AMPK $\alpha 1$ simply became more responsive to stimulation in the ID group than it was in the $C$ group. This increase in AMPK $\alpha 1$ contribution to total AMPK activity is further confirmed by the finding that AMPK $\alpha 2$ expression decreased with iron deficiency, whereas AMPK $\alpha 1$ expression did not change. Together, these data indicate that iron deficiency may cause a shift toward AMPK 1 1 having a greater role in the activity of AMPK in skeletal muscle.

In addition to the alpha subunit composition, the composition of the $\beta$ and $\gamma$ also determine how AMPK responds to energy stress as well as what downstream effectors are regulated. The heterotrimeric composition that is primarily activated in skeletal muscle is the $\alpha 2 / \beta 2$ / $\gamma 3$ combination [33-35]. We report that along with a reduction in the $\alpha 2$ subunit isoform, there is also a marked reduction in the $\alpha 2$ and $\gamma 3$ subunit isoforms in response to iron deficiency. Previous reports looking at changes in the heterotrimeric subunit composition of AMPK have been somewhat mixed. In response to endurance exercise training in rats, one group has reported fast twitch muscles have an increase in the $\gamma 3$ subunit protein content 


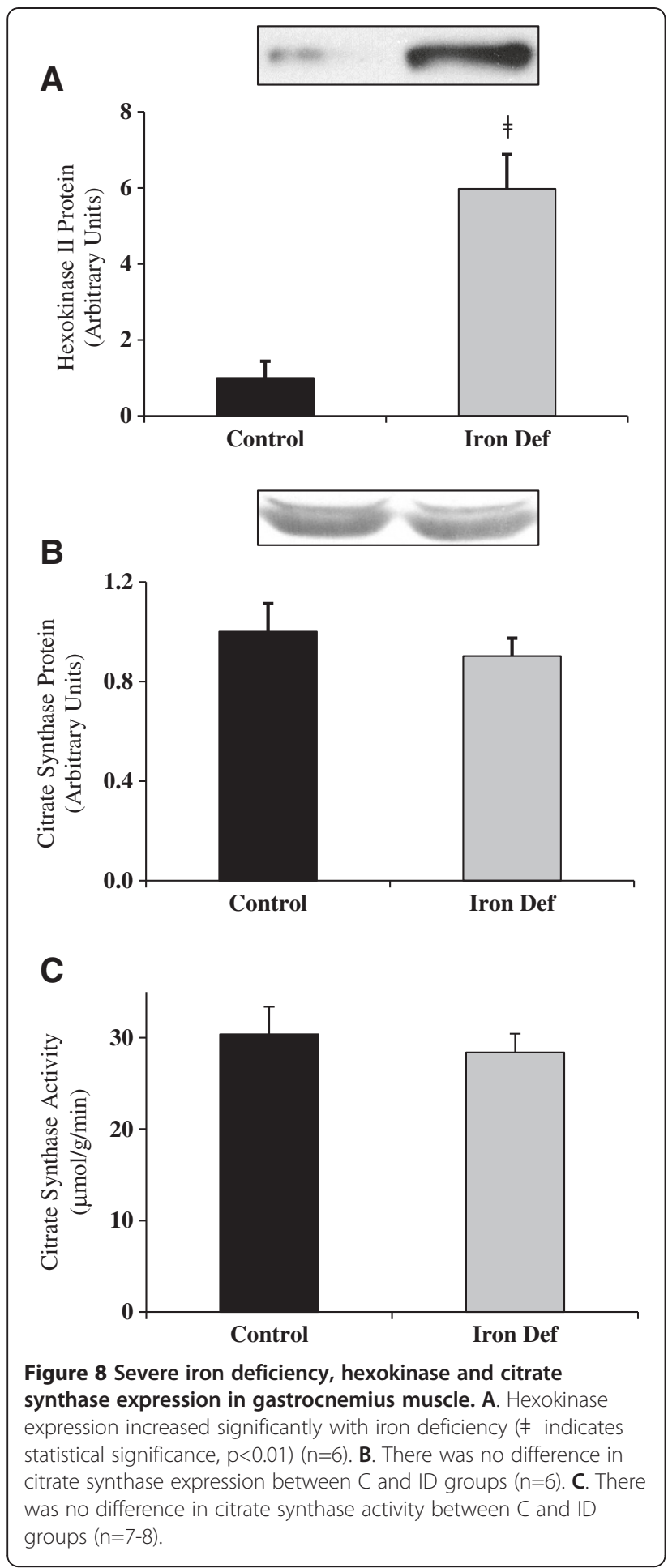

with no change in the $\alpha$ and $\beta$ subunits [36]. Chronic lowfrequency stimulation induces an increase in both $\alpha$ subunits [37]. In human muscle, exercise training has been shown to cause an increase in $\alpha 1, \beta 2$ and $\gamma 1$ subunits and cause a reduction in the $\gamma 3$ subunit $[38,39]$. Interestingly, recent work examining the role of $\gamma 2$ subunit of AMPK suggests that this subunit is critical for AMPK to respond to changes in energy state [40]. Thus, given the reduction observed in the $\beta 2$ subunit with iron deficiency, we might have expected a blunted response to the energy demands of muscle contractions; however we did not observe this. As noted above, the regulatory effect of AMP on AMPK occurs via binding to the $\gamma$ subunit. The $\gamma 3$ isoform has the lowest AMP dependence and the $\gamma 1$ isoform has the greatest AMP dependence [35]. This shift in the gamma subunit isoform expression that we observed (lower $\gamma 3$ while maintaining $\gamma 1$ ) may contribute to the increase in the sensitivity to muscle contractions observed with $\alpha 1$ activity. Overall, the shift in the protein expression of the AMPK subunit composition did not result in a dramatic reduction or increase in AMPK activity at rest or in response to muscle contractions.

\section{Evidence of chronic AMPK activation}

Han et al. showed that iron deficiency causes chronic activation of AMPK [6]. This is not surprising since iron deficiency causes a decrease in the oxygen carrying capacity of blood as well as a decrease in mitochondrial capacity. The stress that this puts on energy metabolism should be enough to cause chronic AMPK activation due to the mild energy demands of normal ambulatory activity. As reflected by the phosphorylation state of AMPK and ACC however, we did not measure such an increase in chronic AMPK activity. This was likely due to the supplementation of the anesthetized rats with pure oxygen ( 40-50 minutes prior to dissection of rested muscles). Based on previous work, this is enough time for any elevation in AMPK activity at rest to return to more normal values [41]. Therefore, due to the length of time during which rested animals were provided with pure oxygen, the effects of iron deficiency on resting muscle AMPK activity were likely masked.

Chronic AMPK activation increases expression of certain mitochondrial and glycolytic enzymes [31,42]. Hexokinase II is regulated by CREB, which can also be phosphorylated by AMPK $[43,44]$. In support of chronic AMPK activation, hexokinase II expression did increase with iron deficiency. In the present study, iron deficiency presents a unique energy challenge in that many oxidative enzymes of the electron transport chain, enzymes that are generally increased by AMPK activation, are iron-dependent, however all irondependent mitochondrial proteins examined were severely reduced due to iron deficiency. Citrate synthase, a noniron dependent mitochondrial enzyme, was not reduced with iron deficiency. Two possible explanations for this result are: 1) AMPK was not chronically activated with iron deficiency, or 2) iron deficiency has an overall negative impact on mitochondrial content, including transcription of all mitochondrial proteins, and chronic AMPK activation actually prevents down-regulation of the non-iron dependent enzymes, rescuing the cell from complete 
mitochondrial deficiency. Due to the known effect of AMPK activation on citrate synthase, further work is needed to determine if AMPK is playing a role in preserving citrate synthase expression.

A decrease in important mitochondrial enzymes, as seen in the present study, reflects a significant decrease in muscle oxidative capacity, and is therefore a possible explanation for the stunted growth seen in the ID rats. Skeletal muscles depend on oxidative phosphorylation far more than any other process for the conversion of nutrients to usable forms of energy. In this case it would be expected that any ingested nutrients would not be efficiently used for the production of ATP necessary for protein synthesis and normal growth.

Previous studies have shown that iron deficiency leads to in increased dependence on glucose metabolism $[1,2]$. The decrease in mitochondrial proteins seen with iron deficiency in previous [27], as well as in the present study, support these findings that iron deficiency causes a shift away from oxidative metabolism. A novel finding shown here is a significant increase in Hexokinase II expression, supporting previous findings that iron deficiency causes a shift toward glycolytic metabolism in order to compensate for the loss of oxidative capacity. As previously stated, chronic AMPK activation increases hexokinase II expression, supporting the idea that AMPK is at least in part responsible for the shift toward glycolytic metabolism seen with iron deficiency. A transgenic model in which AMPK activation is prevented might provide insight into this question.

Another possible explanation for the stunted growth seen in the ID rats is the role of AMPK in inhibition of the actions of mTOR. As previously stated, AMPK $\alpha 1$ is more important than AMPK $\alpha 2$ in the inhibition of protein synthesis via the mTOR pathway [14,32]. This shift toward AMPK $\alpha 1$ having a greater role in total AMPK $\alpha$ activity is another possible explanation for the large difference in body mass between the $\mathrm{C}$ and ID groups. If AMPK $\alpha 1$ proportionally increases with iron deficiency, the mTOR pathway would be further inhibited in ID animals than in $C$ animals, causing increased inhibition of protein synthesis, and therefore decreased growth.

\section{Conclusions}

As a cellular sensor and regulator of energy homeostasis, AMPK senses and responds to many energy challenges, such as iron deficiency, in a variety of ways. Here we provide evidence for a chronic increase in AMPK activity. We also show a decrease in AMPK $\alpha 2, \beta 2$ and $\gamma 3$ AMPK subunits, with no concurrent change in AMPK $\alpha 1, \beta 1, \gamma 1$ or $\gamma 2$ proteins, resulting in an overall shift in AMPK subunit composition. These data suggest that iron deficiency results in a possible shift toward an increase in the role of AMPK $\alpha 1 / \beta 1 / \gamma 1$ heterotrimer dependent signaling in total
AMPK regulation of cellular energy homeostasis. Iron deficiency also causes a shift away from oxidative and toward glycolytic metabolism in rat skeletal muscle. Taken together, these results lead to the question as to whether AMPK is responsible for the metabolic shift seen with iron deficiency. Future work needs to be done in order to determine if such is the case.

\section{Methods}

\section{Animals}

Male Wistar rats were kept in a temperature controlled and well-ventilated room with a 12:12 hour light dark cycle. They were kept in stainless steel mesh wire bottom cages, with no bedding material, and no access to feces. All rats were given free access to distilled water. The iron deficient (ID) group was fed ad libitum and the control (C) group was pair fed to the ID group (see below). All experimental procedures were approved by the institutional animal care and use committee of Brigham Young University.

\section{Body weight}

The rats were weighed 2-3 times per week from the first day on the diets up to, and including the day of sacrifice.

\section{Treatments}

The ID rats were fed an iron deficient diet ad libitum for 6-8 weeks $(n=15)$. The iron deficient diet was obtained from Teklad Lab Animal Diets (Harlan Laboratories, Madison, WI), and consisted of: Casein (low $\mathrm{Cu} \& \mathrm{Fe}$ ), DL-methionine, sucrose, corn starch, corn oil, mineral mix (Fe deficient), vitamin mix, choline bitartrate, ethoxyquin) (TD.80396, contains approximately 2-6 ppm Fe). The C rats were fed the same diet with $48 \mathrm{ppm}$ added iron (TD.80394), pair fed to the ID group for the same period of time $(n=15)$. All rats were approximately 21 days of age on day 0 of treatment.

In situ muscle stimulation was performed as described previously [24]. Briefly, the rat was anesthetized with 60 $\mathrm{mg} / \mathrm{kg}$ sodium pentobarbital ip and the sciatic nerve was isolated and stimulated at rate of 1 twitch contraction per second for 10 minuntes $(0.25 \mathrm{~ms}$ square wave, 6-7 V, using Grass S88X stimulator). In order to limit the oxygen deficit due to reduced hemoglobin in the blood, the anesthetized rat of both $\mathrm{C}$ and ID groups was provided with $100 \%$ oxygen throughout the procedure.

\section{Tissue analysis}

\section{Dissections}

After 6-8 weeks of treatment and right hind-limb stimulation, gastrocnemius, soleus, plantaris, and mixed quadriceps muscles were removed quickly and clamp frozen with liquid nitrogen chilled metal tongs and stored at $-90^{\circ} \mathrm{C}$. The stimulated right hind limb muscles were removed and frozen prior to the rested left hind limb 
muscles. Whole blood was also collected to determine hemoglobin concentration and percent hematocrit (described below).

\section{Muscle contractions}

In order to examine the response of AMPK to an increase in energy demands with and without iron deficiency anemia we performed a mild in situ muscle stimulation protocol. Muscle contractions were elicited using the stimulation procedure via direct stimulation of the sciatic nerve as described previously [24]. This stimulation protocol is sufficient to activate all of the muscle fibers that are innervated by the sciatic nerve. The fatigue profile of the gastrocnemius-plantaris-soleus (GPS) complex of muscles was determined in response to a mild contraction protocol consisting of direct sciatic nerve stimulation at a rate of 1 pulse per second. Muscle force was measured using a force transducer (Grass FT103) and performance data was collected using data acquisition software (iWORX). Following the muscle stimulations, the aforementioned calf muscles were quickly dissected from the right hind-limb and flash-frozen with tongs maintained in liquid nitrogen. Corresponding muscles in the contra-lateral unstimulated limb were subsequently dissected and frozen as rested control muscles.

\section{Homogenization}

Frozen gastrocnemius muscles were pulverized in liquid nitrogen, weighed, and homogenized as a $5 \%$ solution in homogenization buffer $(20 \mathrm{mM}$ Tris- $\mathrm{HCl}, 250 \mathrm{mM}$ Mannitol, $50 \mathrm{mM}$ NaF, $5 \mathrm{mM}$ Sodium Pyrophosphate, 1 mM EDTA, 1 mM EGTA, 1\% Triton X-100, $50 \mathrm{mM} \beta-$ glycerophosphate, $1 \mathrm{mM}$ Sodium Orthovanadate, $1 \mathrm{mM}$ DTT, $1 \mathrm{mM}$ Benzamadine, $0.1 \mathrm{mM}$ PMSF, $5 \mathrm{\beta g} / \mathrm{ml}$ Soybean Trypsin Inhibitor, pH 7.4) (50 mg muscle powder $/ 1 \mathrm{ml}$ buffer) then stored in $-90^{\circ} \mathrm{C}$ freezer.

\section{Packed cell volume (hematocrit)}

Blood was taken from the tail 4 weeks after the start of feeding, and once weekly after that, to determine degree of iron deficiency anemia. This was done by drawing blood into a capillary tube and centrifuging for $5 \mathrm{~min}$ at $14,500 \mathrm{rpm}$.

\section{Protein quantification}

The standard Lowry Protein Assay protocol (BioRad, Hercules, CA) was used to measure the protein concentration in each muscle homogenate so that an equal amount of protein was added to each well for electrophoresis.

\section{Hemoglobin quantification}

A hemoglobin quantification assay was used to determine the degree of anemia reached in the ID rats versus the $C$ rats on the day of sacrifice as previously described $[45,46]$.
Briefly, known concentration hemoglobin standards were made by adding the appropriate amount of hemoglobin to the appropriate volume of Drabkin's solution (1 vial of Drabkin's reagent with $1000 \mathrm{ml}$ water and $0.5 \mathrm{ml}$ Brij 35 Solution). Abs $_{540 \mathrm{~nm}}$ was recorded and used to make a linear standard curve. Whole blood samples were diluted 10fold in $0.9 \% \mathrm{NaCl}$ solution. $2.5 \mathrm{ml}$ Drabkin's solution was added to a series of test tubes. $10 \mu \mathrm{l}$ of whole blood sample was added to each test tube and allowed to sit for 15 min at room temperature. Abs $_{540 n m}$ was recorded and compared with standard curve to determine hemoglobin concentration of each sample.

\section{AMPK activity assay}

An AMPK Activity Assay was used to directly measure and compare the amount of AMPK that was activated in the different experimental groups. The protocol used was described previously $[21,47]$. Briefly, immunoprecipitation was performed on spun muscle homogenates in order to isolate $\mathrm{AMPK} \alpha 1$ and $\mathrm{AMPK} \alpha 2$ with the appropriate antibodies (AMPK $\alpha 1$ 1:10,000 from Bethyl - cat. no. A300-507A; AMPK $\alpha 2$ 1:4,000 from Bethyl - cat. no. A300-508A). AMPK activity was quantitated by measuring the rate of incorporation of radiolabeled phosphate from ATP into an artificial peptide substrate (SAMS) with a sequence similar to that of liver acetyl-CoA carboxylase, a natural substrate for AMPK.

\section{Citrate synthase activity assay}

A citrate synthase assay was used to measure the difference in activity of the enzyme between the $C$ group and the ID group as previously described by Srere [48].

\section{Western Blot}

Standard Western blot protocol was used. Western blot analysis was performed on gastrocnemius muscles for AMPK $\alpha 1$ (1:10,000 from Bethyl; cat. no. A300-507A), AMPK 22 (1:4,000 from Bethyl; cat. no. A300-508A), AMPK $\beta 1$ (1:4,000 from Cell Signaling; cat. no. 4182), AMPK 32 (1:4,000 from Cell Signaling; cat. no. 4148), АMPKү1 (1:4,000 from Cell Signaling; cat. no. 4187), AMPK 2 (1:2,000 from Santa Cruz; cat. no. 20165), AMPK $\gamma 3$ (1:2,000 custom made from Affinity Bioreagents), AMPK pan $\alpha$ (1:2,000 from Cell Signaling; cat. no. 2532L), phosphoAMPK $\alpha$ (1:1,000 from Cell Signaling; cat. no. 4188L), ACC (1:2,000 from Cell Signaling; cat. no. 3662), phosphoACC (1:5,000 from Cell Signaling; cat. no. 3661S), hexokinase II (1:10,000 from Santa Cruz; cat. no. sc-6521), myoglobin (1:3,000 from Santa Cruz; cat. no. sc25607), cytochrome c oxidase complex 1 (COX-1) and succinate dehydrogenase (1,5:000 OxPhos Cocktail Ab from Invitrogen; cat. no. 458009), and cytochrome c (1:5,000 from Sigma; cat. no. C5723). Western blot analysis was also performed on mixed quadriceps muscle for citrate synthase (1:10,000 from Alpha Diagnostic; cat. no. CISY11-A). 


\section{High Performance Liquid Chromatography (HPLC)}

Preparation of tissues for HPLC were done using the Perchlorate Tissue Extraction method as described by Chen [49]. Briefly, muscles were ground to powder at liquid nitrogen temperature and then homogenized in $3.5 \%$ perchloric acid in a volume 19 times the wet weight of the muscle. The homogenates were then centrifuged at $12,000 \mathrm{rpm}$ for $7 \mathrm{~min}$ to remove protein. This was followed by neutralization of the supernatant with tri-n-octylamine and 1,1,2-trichlorotrifluoroethane. After vortexing for 1 $\mathrm{min}$, the neutralized homogenates were again centrifuged at 2,000 rpm for $7 \mathrm{~min}$. The top phase was saved, checked for $\mathrm{pH}$ (it should be between 5.5-6.5), and stored at $-80^{\circ} \mathrm{C}$. Adenine nucleotides (ATP, ADP, AMP) and IMP were quantified by reverse-phase HPLC, as described by Tullson et al. [50]. Phospocreatine ( $\mathrm{PCr})$ and creatine $(\mathrm{Cr})$ concentrations were measured by ion exchange HPLC as described by Wiseman and colleagues [51].

Free ADP $\left(\left[\mathrm{ADP}_{\mathrm{f}}\right]\right)$ and free AMP concentrations $\left(\left[\mathrm{AMP}_{\mathrm{f}}\right]\right)$ were estimated based on the following equations

$$
\left[\mathrm{ADP}_{\mathrm{f}}\right]=[\mathrm{ATP}][\text { creatine }] / K_{\mathrm{obs}}\left[\mathrm{H}^{+}\right][\text {phosphocreatine }]
$$

where $K_{\text {obs }}=1.66 \times 10^{-6} \mathrm{mM}^{-1}$, and assuming $76 \%$ water, and $14 \%$ vascular volume [52]

$$
\left[\mathrm{AMP}_{\mathrm{f}}\right]=\left[\mathrm{ADP}_{\mathrm{f}}\right]^{2} / K_{\mathrm{obs}}[\mathrm{ATP}]
$$

where $K_{\text {obs }}=1.05 \times 10$ [53]. $\mathrm{pH}$ was assumed to be 7 in rested animals [53] however based on the differences in phosphocreatine, fatigue, and IMP accumulation, we estimated $\mathrm{pH}$ to be 6.6 in the $\mathrm{C}$ animals following stimulation and 6.2 in the ID animals following stimulation [53].

\section{Statistics}

For comparisons including iron deficiency and muscle stimulation (4 different groups) two-way analysis of variance was used. Fisher's least significant difference post-hoc test was applied where appropriate. When making a simple comparison between ID and $\mathrm{C}$ a student's t-test was used. SigmaStat statistical software was used. Statistical significance is defined as $\mathrm{p}<0.05$. Results are presented as means \pm SEM.

Competing interests

The authors declare that there are no competing interests.

\section{Authors' contributions}

CRH and JFM, conceived of the study and participated in its design, data collection, analysis and writing of the manuscript. DMT participated in the study design and writing of the manuscript. SDH and SW collected data and analyzed results. All authors read and approved the final manuscript.

\section{Acknowledgements}

This research was supported in part by the National Institute of Arthritis and Musculoskeletal and Skin Diseases Grant AR-051928. Dr. Jiping Zou contributed technical assistance. We would also like to thank William W. Winder for thoughtful and productive discussions and input.

\section{Author details}

'Department of Physiology and Developmental Biology, Brigham Young University, Provo, Utah, USA. ²Department of Nutrition, Dietetics, and Food Science, Brigham Young University, Provo, Utah, USA.

Received: 7 June 2012 Accepted: 16 November 2012 Published: 21 November 2012

\section{References}

1. Brooks GA, Henderson SA, Dallman PR: Increased glucose dependence in resting, iron-deficient rats. Am J Physiol 1987, 253:E461-E466.

2. Henderson SA, Dallman PR, Brooks GA: Glucose turnover and oxidation are increased in the iron-deficient anemic rat. Am J Physiol 1986, 250:E414-E421.

3. Corton JM, Gillespie JG, Hardie DG: Role of the AMP-activated protein kinase in the cellular stress response. Curr Biol 1994, 4:315-324.

4. Worldwide prevalence of anaemia 1993-2005: WHO Global Database on Anaemia. In Book Worldwide prevalence of anaemia 1993-2005: WHO Global Database on Anaemia. Edited by Benoist B, McLean E, Egli I, Cogswell M. Geneva, Switzerland: World Health Organization; 2002.

5. Davies KJ, Maguire JJ, Brooks GA, Dallman PR, Packer L: Muscle mitochondrial bioenergetics, oxygen supply, and work capacity during dietary iron deficiency and repletion. Am J Physiol 1982, 242:E418-E427.

6. Han DH, Hancock CR, Jung SR, Higashida K, Kim SH, Holloszy JO: Deficiency of the mitochondrial electron transport chain in muscle does not cause insulin resistance. PLOS One 2011, 6:e19739.

7. Hue L, Rider MH: The AMP-activated protein kinase: more than an energy sensor. Essays Biochem 2007, 43:121-137.

8. Karagounis LG, Hawley JA: The 5' adenosine monophosphate-activated protein kinase: regulating the ebb and flow of cellular energetics. Int J Biochem Cell Biol 2009, 41:2360-2363.

9. Hardie DG, Carling D: The AMP-activated protein kinase-fuel gauge of the mammalian cell? European J Biochemistry / FEBS 1997, 246:259-273.

10. Kemp BE, Mitchelhill KI, Stapleton D, Michell BJ, Chen ZP, Witters LA Dealing with energy demand: the AMP-activated protein kinase. Trends Biochem Sci 1999, 24:22-25.

11. Hardie DG, Carling D, Sim ATR: The Amp-Activated Protein-Kinase - a Multisubstrate Regulator of Lipid-Metabolism. Trends Biochem Sci 1989, $14: 20-23$.

12. Salt I, Celler JW, Hawley SA, Prescott A, Woods A, Carling D, Hardie DG: AMP-activated protein kinase: greater AMP dependence, and preferential nuclear localization, of complexes containing the alpha2 isoform. Biochem J 1998, 334(Pt 1):177-187.

13. Mounier R, Lantier L, Leclerc J, Sotiropoulos A, Foretz M, Viollet B: Antagonistic control of muscle cell size by AMPK and mTORC1. Cell Cycle 2011, 10:2640-2646

14. Mounier R, Lantier L, Leclerc J, Sotiropoulos A, Pende M, Daegelen D, Sakamoto K, Foretz M, Viollet B: Important role for AMPKalpha1 in limiting skeletal muscle cell hypertrophy. FASEB J 2009, 23:2264-2273.

15. Hawley SA, Boudeau J, Reid JL, Mustard KJ, Udd L, Makela TP, Alessi DR, Hardie DG: Complexes between the LKB1 tumor suppressor, STRAD alpha/beta and MO25 alpha/beta are upstream kinases in the AMPactivated protein kinase cascade. J Biol 2003, 2:28.

16. Shaw RJ, Kosmatka M, Bardeesy N, Hurley RL, Witters LA, DePinho RA, Cantley LC: The tumor suppressor LKB1 kinase directly activates AMPactivated kinase and regulates apoptosis in response to energy stress. Proc Natl Acad Sci U S A 2004, 101:3329-3335.

17. Cheung PC, Salt IP, Davies SP, Hardie DG, Carling D: Characterization of AMP-activated protein kinase gamma-subunit isoforms and their role in AMP binding. Biochem J 2000, 346(Pt 3):659-669.

18. Suter M, Riek U, Tuerk R, Schlattner U, Wallimann T, Neumann D: Dissecting the role of 5'-AMP for allosteric stimulation, activation, and deactivation of AMP-activated protein kinase. J Biol Chem 2006, 281:32207-32216.

19. Carling D, Sanders MJ, Woods A: The regulation of AMP-activated protein kinase by upstream kinases. Int J Obes (Lond) 2008, 32 (Suppl 4):S55-S59.

20. Carling D, Mayer FV, Sanders MJ, Gamblin SJ: AMP-activated protein kinase: nature's energy sensor. Nat Chem Biol 2011, 7:512-518.

21. Winder WW, Hardie DG: Inactivation of acetyl-CoA carboxylase and activation of AMP-activated protein kinase in muscle during exercise. Am J Physiol 1996, 270:E299-E304. 
22. Park SH, Gammon SR, Knippers JD, Paulsen SR, Rubink DS, Winder WW Phosphorylation-activity relationships of AMPK and acetyl-CoA carboxylase in muscle. J Appl Physio/ 2002, 92:2475-2482.

23. Hancock CR, Brault JJ, Wiseman RW, Terjung RL, Meyer RA: 31P-NMR observation of free ADP during fatiguing, repetitive contractions of murine skeletal muscle lacking AK1. Am J Physiol Cell Physiol 2005, 288:C1298-C1304.

24. Hancock CR, Janssen E, Terjung RL: Skeletal muscle contractile performance and ADP accumulation in adenylate kinase-deficient mice. Am J Physiol Cell Physiol 2005, 288:C1287-C1297.

25. Marsin AS, Bouzin C, Bertrand L, Hue L: The stimulation of glycolysis by hypoxia in activated monocytes is mediated by AMP-activated protein kinase and inducible 6-phosphofructo-2-kinase. J Biol Chem 2002, 277:30778-30783.

26. McLane JA, Fell RD, McKay RH, Winder WW, Brown EB, Holloszy JO: Physiological and biochemical effects of iron deficiency on rat skeletal muscle. Am J Physiol 1981, 241:C47-C54.

27. Willis WT, Brooks GA, Henderson SA, Dallman PR: Effects of iron deficiency and training on mitochondrial enzymes in skeletal muscle. J Appl Physiol 1987, 62:2442-2446.

28. Jensen TE, Wojtaszewski JF, Richter EA: AMP-activated protein kinase in contraction regulation of skeletal muscle metabolism: necessary and/or sufficient? Acta Physiol (Oxf) 2009, 196:155-174.

29. Mackie $B G$, Terjung RL: Blood flow to different skeletal muscle fiber types during contraction. Am J Physiol 1983, 245: $\mathrm{H} 265-\mathrm{H} 275$.

30. Hardie DG, Carling D, Gamblin SJ: AMP-activated protein kinase: also regulated by ADP? Trends Biochem Sci 2011, 36:470-477.

31. Winder WW, Holmes BF, Rubink DS, Jensen EB, Chen M, Holloszy JO: Activation of AMP-activated protein kinase increases mitochondrial enzymes in skeletal muscle. J Appl Physiol 2000, 88:2219-2226.

32. McGee SL, Mustard KJ, Hardie DG, Baar K: Normal hypertrophy accompanied by phosphoryation and activation of AMP-activated protein kinase alpha1 following overload in LKB1 knockout mice. J Physiol 2008, 586:1731-1741.

33. Yu H, Fujii N, Hirshman MF, Pomerleau JM, Goodyear LJ: Cloning and characterization of mouse 5'-AMP-activated protein kinase gamma3 subunit. Am J Physiol Cell Physiol 2004, 286:C283-C292.

34. Birk JB, Wojtaszewski JF: Predominant alpha2/beta2/gamma3 AMPK activation during exercise in human skeletal muscle. J Physiol 2006, 577:1021-1032.

35. Durante PE, Mustard KJ, Park SH, Winder WW, Hardie DG: Effects of endurance training on activity and expression of AMP- activated protein kinase isoforms in rat muscles. Am J Physiol Endocrinol Metab 2002, 283:178-186.

36. Putman CT, Martins KJ, Gallo ME, Lopaschuk GD, Pearcey JA, MacLean IM, Saranchuk RJ, Pette D: Alpha-catalytic subunits of 5'AMP-activated protein kinase display fiberspecific expression and are upregulated by chronic low-frequency stimulation in rat muscle. Am J Physiol Regul Integr Comp Physiol 2007, 293:R1325-R1334.

37. Frosig C, Jorgensen SB, Hardie DG, Richter EA, Wojtaszewski JF: 5'-AMPactivated protein kinase activity and protein expression are regulated by endurance training in human skeletal muscle. Am J Physiol Endocrinol Metab 2004, 286:E411-E417.

38. Wojtaszewski JF, Birk JB, Frosig C, Holten M, Pilegaard H, Dela F: 5'AMP activated protein kinase expression in human skeletal muscle: effects of strength training and type 2 diabetes. J Physiol 2005, 564:563-573.

39. Dasgupta B, Ju JS, Sasaki Y, Liu X, Jung SR, Higashida K, Lindquist D, Milbrandt J: The AMPK beta2 subunit is required for energy homeostasis during metabolic stress. Mol Cell Biol 2012, 32:2837-2848.

40. Rasmussen BB, Hancock CR, Winder WW: Postexercise recovery of skeletal muscle malonyl-CoA, acetyl-CoA carboxylase, and AMP-activated protein kinase. J Appl Physiol 1998, 85:1629-1634.

41. Fillmore N, Jacobs DL, Mills DB, Winder WW, Hancock CR: Chronic AMPactivated protein kinase activation and a high-fat diet have an additive effect on mitochondria in rat skeletal muscle. J App/ Physio/ 2010, 109:511-520.

42. Stoppani J, Hildebrandt AL, Sakamoto K, Cameron-Smith D, Goodyear L, Neufer PD: AMP-activated protein kinase activates transcription of the UCP3 and HKIl genes in rat skeletal muscle. Am J Physiol Endocrinol Metab 2002, 283:E1239-E1248.
43. Thomson DM, Herway ST, Fillmore N, Kim H, Brown JD, Barrow JR, Winder WW: AMP-activated protein kinase phosphorylates transcription factors of the CREB family. J Appl Physiol 2008, 104:429-438.

44. Stadie WC: A method for the determination of methemoglobin in whole blood. J Biol Chem 1920, 41.

45. Drabkin DL, Austin JH: Spectrophotometric studies. II. Preparations from washed blood cells; nitric oxide hemoglobin and sulfhemoglobin. J Biol Chem 1935, 112:51-65.

46. Davies SP, Carling D, Hardie DG: Tissue distribution of the AMP-activated protein kinase, and lack of activation by cyclic-AMP-dependent protein kinase, studied using a specific and sensitive peptide assay. European J Biochemistry / FEBS 1989, 186:123-128.

47. Srere PA: Citrate Synthase. Methods in Enzymology. 1969, 13:3-6.

48. Chen SC, Brown PR, Rosie DM: Extraction procedures for use prior to HPLC nucleotide analysis using microparticle chemically bonded packings. J Chromatogr Sci 1977, 15:218-221.

49. Tullson PC, Whitlock DM, Terjung RL: Adenine nucleotide degradation in slow-twitch red muscle. Am J Physiol 1990, 258:C258-C265

50. Wiseman RW, Moerland TS, Chase PB, Stuppard R, Kushmerick MJ: Highperformance liquid chromatographic assays for free and phosphorylated derivatives of the creatine analogues beta-guanidopropionic acid and 1-carboxy-methyl-2-iminoimidazolidine (cyclocreatine). Anal Biochem 1992, 204:383-389.

51. Hood DA, Terjung RL: Leucine metabolism in perfused rat skeletal muscle during contractions. Am J Physiol 1987, 253:E636-E647.

52. Dudley GA, Terjung RL: Influence of acidosis on AMP deaminase activity in contracting fast-twitch muscle. Am J Physiol 1985, 248:C43-C50.

53. Lawson JW, Veech RL: Effects of $\mathrm{pH}$ and free $\mathrm{Mg} 2+$ on the Keq of the creatine kinase reaction and other phosphate hydrolyses and phosphate transfer reactions. J Biol Chem 1979, 254:6528-6537.

\section{doi:10.1186/1743-7075-9-104}

Cite this article as: Merrill et al.: Iron deficiency causes a shift in AMPactivated protein kinase (AMPK) subunit composition in rat skeletal muscle. Nutrition \& Metabolism 2012 9:104.

\section{Submit your next manuscript to BioMed Central and take full advantage of:}

- Convenient online submission

- Thorough peer review

- No space constraints or color figure charges

- Immediate publication on acceptance

- Inclusion in PubMed, CAS, Scopus and Google Scholar

- Research which is freely available for redistribution 